\title{
EVALUATION OF CYTOTOXICITY OF DIFFERENT UNIVERSAL BONDS USING THE XCELLIGENCE SYSTEM
}

\begin{abstract}
Objectives: The purpose of this study was to explore the cytotoxic effects of five different universal bonding agents on mouse fibroblast cell lines (L929).
\end{abstract}

Materials and Methods: Five different widely used universal adhesive systems were chosen that have different contents, $\mathrm{pH}$ levels, and polymerization methods. A real-time cell analyzer (RT-CES, xCELLigence; Roche Applied Science, Germany, and ACEA Biosciences, USA) was used for cytotoxic evaluation of light-cured polymerized G-Premio Bond (GC Europe, Belgium), Prime\&Bond Universal (Dentsply Sirona, USA), Universal Bond Quick (Kuraray, USA), Single Bond Universal (3M ESPE, USA) and self-cured polymerized Tokuyama Universal Bond (Tokuyama, USA) experimental groups. L929 were cultured in Dulbecco's modified Eagle's medium and supplemented with $10 \%$ fetal bovine serum and 1 $\%$ antibiotics. The assay was performed E-plate-16 and monitored every $15 \mathrm{~min}$ for $72 \mathrm{~h}$. Statistical analysis was performed using ANOVA and Tukey's posthoc tests.

Results: All tested universal adhesive systems showed a statistically significant difference in cytotoxicity values in different periods $(\mathrm{p}<0.05)$. Among the groups compared, G-Premio Bond showed the least cytotoxic effect; and Tokuyama Universal Bond showed the most cytotoxic effect. Different times of all universal adhesive systems significantly increased the count of viable cells compared to the control group $(\mathrm{p}<0.05)$.

Conclusions: In dentistry, universal adhesive systems can be observed cytotoxic effects to live cells. The evaluation of cytotoxicity with xCELLigence device is a reliable method and should be supported by new studies on this subject.

Keywords: xCELLigence, cytotoxicity, universal adhesive systems, L929.
*Sevim Atilan Yavuz ${ }^{1}$

Derya Surmelioglu ${ }^{1}$

ORCID IDs of the authors:

S.A.Y. 0000-0002-6192-4931

D.S. 0000-0002-6034-3131

${ }^{1}$ Department of Restorative Dentistry, Faculty of Dentistry, Gaziantep University, Şehitkamil, Gaziantep, Turkey.

Received : : 10.09 .2020

Accepted $\quad: 25.11 .2020$ 


\section{INTRODUCTION}

Currently, there is increasing social awareness around the importance of health and wellness. This situation allows improves physicians' working conditions while at the same time providing patients more aesthetic, functional, and longerlasting restorations. As a result of these developments, new researches are added to the literature with the study of both clinicians and academicians on aesthetic materials.

Dentin bonding agents can improve bonding strength, increase the adhesion of restorations, reduce micro-leakage between the tooth-resin interface, and decrease occlusal stress. ${ }^{1}$ Initially, in the clinical resin restorative system, bonding agents were applied in three steps. However, several manufacturers have reduced the bonding procedure to two steps by introducing both the adhesive and the primary solvent in a single bottle. ${ }^{2}$ Furthermore, in some systems, the acid, primer, and adhesive are incorporated into the same bottle to make a single-step or self-etching primer bonding system. ${ }^{3}$ More recently, single-step universal adhesive systems have been developed which can be used in three different modes such as self-etch, selective etch, and total-etch. ${ }^{4}$

Although these adhesive systems are similar in terms of their monomers' composition, universal adhesive systems differ from other adhesive systems by their monomers that can establish chemical and micromechanical bonds. ${ }^{5}$ Another property of universal adhesive is strong adhesion to enamel due to unique $\mathrm{COOH}$ or $\mathrm{PO}_{4}$ monomers that ionically bond to the calcium in the hydroxyapatite crystals of the enamel. ${ }^{6}$ Additionally, the MDP monomer, which is only present in universal adhesives, allows universal systems to be used with three different etching techniques. $^{7}$

All adhesive systems such as self-etch, totaletch, and universal adhesive systems have different compositions, $\mathrm{pH}$ levels, and polymerization techniques. ${ }^{8,9}$ In several studies in the literature, it has been reported that all these parameters are associated with cytotoxicity of adhesive systems in teeth and living tissues. ${ }^{10-12}$ Although the purpose of adhesive systems is to provide bonding of restorative materials to enamel/ dentin, it is also important to investigate the potential cytotoxic effects due to the various monomers contain in adhesive systems. Adhesive systems typically include monomers such as bisphenol A-glycidyl methacrylate (Bis-GMA), urethane dimethacrylate (UDMA), triethylene glycol dimethacrylate (TEGDMA), hydroxy ethyl methacrylate (HEMA) and dipenta erythritol penta-acrylate monophosphate (PENTA). Additionally, some contain biphenyl dimethacrylate (BPDM) and polyalkenoic acid. ${ }^{13,14}$

Hydrophobic monomers such as Bis-GMA and UDMA show more cytotoxic effects compared to hydrophilic monomers such as HEMA and TEGDMA. ${ }^{15}$ Progress of hydrophilic monomers in dentinal fluid and transporting hydrophobic monomers in dentin tubules can cause cytotoxic effects in pulp. Furthermore, the toxic effects of hydrophilic and hydrophobic groups together are greater than the toxic effects they produce alone. ${ }^{16}$ While resin-based dental materials have a local cytotoxic effect on pulp, systemic toxicity has not been observed in previous studies. ${ }^{17,18}$

The acidic characteristic of monomers in universal adhesive systems allows for the simultaneous creation of diffusion channels and the infiltration of these channels. Recently, new universal adhesive systems have been marketed with $\mathrm{pH}$ values, but there is not enough search about exposing the dentin complex to these agents. However, it is generally known that due to the cytotoxicity of bonding agents ${ }^{19-22}$, there is the possibility of pulpal damage in clinical applications. Therefore, it is recommended for clinicians to use etch-rinse systems in shallow cavities and self-etch systems in deep cavities. ${ }^{23}$

The polymerization of resin monomers is important in terms of biocompatibility and bonding strength in bonding systems. HEMA and UDMA, which are hydrophilic monomers, provide better resin infiltration, increase bond strength and provide sufficient polymerization of monomers. ${ }^{24,25}$ The effect of different polymerization types on polymerization is also an important question since it is known that residual monomer release increases due to inadequate polymerization. ${ }^{26,27}$ Researches 
have been conducted on the effects of universal adhesives with either light-cured or self-cured polymerization types on cytotoxicity because, in the bonding process, unreacted resin monomers can damage the pulp tissue through dentine tubules. ${ }^{12,28}$ Although there are significant developments and innovations about the physical and mechanical properties of adhesive systems day to day, the biocompatibility of these systems in tooth and living tissues has not yet been fully characterized. In this study, a real-time cell analyzer (xCELLigence) was used to investigate the time-dependent cytotoxic effects of five different universal dentin bonding agents on a mouse fibroblast cell line (L929). In addition, little is known about the cytotoxicity of universal adhesive systems. This research is the first study in the literature in which the cytotoxicity of different universal adhesive systems is evaluated by the xCELLigence method.

Our study aims to evaluate the cytotoxic effects of five different universal bonding agents on mouse fibroblast cell lines (L929). The null hypothesis was all five different universal adhesive systems with different monomer content, $\mathrm{pH}$ level, and polymerization technique will have different cytotoxic effects.

\section{MATERIALS AND METHODS}

This study was approved by the Ethics Committee of Gaziantep University (process no. 2018/374).

\section{Experimental Groups}

Five different universal dentin bonding agents were tested in this experiment: G-Premio Bond (GC Europe, Inc., Leuven, Belgium), Tokuyama Universal Bond (Tokuyama America, Inc., California, USA), Universal Bond Quick (Kuraray America, Inc., Texas, USA), Prime\&Bond Universal (Dentsply Sirona, Inc., Pennsylvania, USA) and Single Bond Universal (3M/ESPE, Inc., Minnesota, USA). Materials and ingredients are provided in Table 1.

Table 1. Materials used in this study

\begin{tabular}{|c|c|c|c|}
\hline Adhesive Systems & Components & Manufacturer & pH \\
\hline G-Premio Bond & $\begin{array}{l}\text { MDP, 4-MET, Methacrylate monomer, } \\
\text { acetone, water, silane }\end{array}$ & $\begin{array}{l}\text { GC Europe (Leuven, } \\
\text { Belgium) }\end{array}$ & 1.5 \\
\hline Tokuyama Universal Bond & $\begin{array}{l}\text { Bis-GMA, TEGDMA, HEMA, } \\
\text { isopropanol, acetone, water }\end{array}$ & $\begin{array}{l}\text { Tokuyama (California, } \\
\text { USA) }\end{array}$ & 2.2 \\
\hline Universal Bond Quick & $\begin{array}{l}\text { Bis-GMA, HEMA, MDP, hydrophilic } \\
\text { amide monomer, ethanol, water, silane }\end{array}$ & Kuraray (Texas, USA) & 2.3 \\
\hline Prime\&Bond Universal & $\begin{array}{l}\text { PENTA,10-MDP, isopropanol, acetone, } \\
\text { water }\end{array}$ & $\begin{array}{l}\text { Dentsply Sirona } \\
\text { (Pennsylvania, USA) }\end{array}$ & $\sim 2.5$ \\
\hline Single Bond Universal & $\begin{array}{l}\text { 2-HEMA, 10-MDP, dimethacrylate } \\
\text { resins, VitrebondTM copolymer, silane, } \\
\text { filler, ethanol, water, initiators. }\end{array}$ & $\begin{array}{l}\text { 3M ESPE (Minnesota, } \\
\text { USA) }\end{array}$ & 2.7 \\
\hline
\end{tabular}

Test specimens were prepared according to the manufacturers' instructions. In addition to the five different experimental groups, a control group containing only the L929 fibroblast cell line (ATCC®CRL-6364) without any adhesive material was added.

In order to obtain the cytotoxic values of the adhesive systems used, preparation of test samples, sterilization, preparation of cell culture, and evaluation with the xCELLigence method were performed. All processes were accomplished in accordance with the ISO 10993-5 protocol to ensure standardization. ${ }^{10}$ Polymerization of universal dentin bonding systems was achieved by using a LED (Valo Led, Ultradent) light device at times recommended according to the manufacturer's instructions (with the exception of self-cured Tokuyama Universal Bond).

\section{Cell Culture}

An established cell lines, mouse fibroblasts L929 (American Type Culture Collection CCL 1), was cultivated in Dulbecco's Modified Eagle's 
Medium (DMEM; Invitrogen, Carlsbad, CA, United States) including 10\% fetal bovine serum (FBS) and $1 \%$ antibiotics (100 IU/ $\mathrm{mL}$ penicillinstreptomycin). Cultures were maintained at $37{ }^{\circ} \mathrm{C}$ in a humidified atmosphere of $5 \% \mathrm{CO}_{2}$ and $95 \%$ air.

Cells grown in flasks were passaged twice a week until the required cell density for the cytotoxicity test was maintained at $37{ }^{\circ} \mathrm{C}$ in a

Table 2. Cell culture medium used in this study

\begin{tabular}{cc}
\hline CELL CULTURE MEDIUM & MANUFACTURER \\
\hline Dulbecco's Modified Eagle Medium & Sigma Aldrich Chemie, Germany \\
Fetal Bovine Serum & Biochrom KG, Germany \\
Penicillin /Streptomycin & Biochrom KG, Germany \\
\hline
\end{tabular}

\section{Cell Count}

The hemocytometer was used to calculate the number of cells in milliliters of the suspension, using the following formula:

Total cell count $/ \mathrm{ml}=$ hemocytometer count result x $10^{4} \mathrm{x}$ medium amount $(\mathrm{ml})$

\section{Preparation of Extraction Fluid and Extraction Process}

In this study, artificial saliva was preferred as extraction fluid. The content of the saliva solution was; $136.8 \mathrm{mM} \mathrm{NaCl}$ (sodium chloride), $3.0 \mathrm{mM}$ $\mathrm{KCl}$ (potassium chloride), $2.5 \mathrm{mM} \mathrm{CaCl} 2.6 \mathrm{H}_{2} \mathrm{O}$ (calcium chloride), $\quad 1.5 \mathrm{mM} \quad \mathrm{MgCl}_{2} \cdot 6 \mathrm{H}_{2} \mathrm{O}$ (magnesium chloride), $0.5 \mathrm{mM} \mathrm{Na} \mathrm{SO}_{4} \cdot 10 \mathrm{H}_{2} \mathrm{O}$ (sodium sulfate), $4.2 \mathrm{mM} \mathrm{NaHCO}_{3}$ (sodium bicarbonate), and $1.0 \mathrm{mM} \quad \mathrm{K}_{2} \mathrm{HPO}_{4} \cdot 3 \mathrm{H}_{2} \mathrm{O}$ (dipotassium phosphate).

The prepared test samples were placed in an Eppendorf tube, then $1 \mathrm{ml}$ artificial saliva solution was added. Since the extraction liquid to be obtained after all these extraction procedures will be applied to cell cultures, the following procedures were performed in a laminar flow cabinet with UV light sterilization. The extracts were placed in different Eppendorfs tubes due to the various waiting time ( $24 \mathrm{~h}, 48 \mathrm{~h}$ and $72 \mathrm{~h}$ ) of the samples.

\section{xCELLingence System}

The xCELLigence system is a method for measuring cell viability in accordance with the manufacturer's instructions. (Roche Diagnostics GmbH, Mannheim, Germany and ACEA humid atmosphere. A solution containing $0.05 \%$ trypsin and $0.53 \mathrm{mM}$ ethylenediamine tetra acetic acid (EDTA) was used to remove the cells from the flasks. All protocols were performed in a laminar flow cabinet with UV light sterilization. DMEM was added to the suspended cells to neutralize the shown in Table 2. effect of trypsin. The medium and manufacturer are
Biosciences, Inc., San Diego, CA, USA). The xCELLigence system consists the real time analyser (RTCA), the RTCA single plate (SP) station, the RTCA computer with integrated software and a disposable E-plate 16. While the RTCA SP station fits inside a standard tissueculture incubator, the measurements are transferred to a software analyser and computer. The E-plate 16 is a disposable device used for performing cellbased assays on the RTCA SP instrument. The single-use E-plate 16 contains gold cell sensor arrays at the bottom which; contributes to the monitoring and testing the cells in each well. The E-plate 16 has a low evaporation lid design: the bottom diameter of each well is $5.0 \mathrm{~mm} \pm 0.05 \mathrm{~mm}$; with a total volume of $243 \pm 5 \mu \mathrm{L}$. Approximately $80 \%$ of the bottom of each well is covered by circle-on-line-electrodes, which are designed to be used in an environment of +15 to $+40{ }^{\circ} \mathrm{C}$, relative humidity $98 \%$ maximum without condensation.

Physiological changes of the cells to be examined are determined by the electronic impedance formed in the sensor electrodes. The voltage of the electrodes is about $20 \mathrm{mV}$ (RMS) during the test. In the absence of cells, the main source of electrode impedance is the concentration of ions at both the electrode / solution interface and within the solution. In the presence of cells, which act as insulators, the electrode impedance increases as a result of the change in the local ion environment at the electrode / solution interface. The electrode impedance value changes in proportion to the cell density. 


\section{Cytotoxicity Test}

In this study, a 16-well E-plate 16 was used; each well had a volume of $250 \mu \mathrm{L}$ and a base diameter of $5 \mathrm{~mm}$. After $200 \mu \mathrm{L}$ of the cell suspensions were seeded into the wells (10.000 cells/well) of the Eplate 16 in a laminar flow cabinet with UV light sterilization, and the plates were placed in the incubator. L929 mouse fibroblast cells which were placed on the well of the plates was provided to grow in the appropriate medium and $\mathrm{O}_{2} / \mathrm{CO}_{2}$ environment, to enter the rapid growth phase (log phase). In addition to the experimental groups, only the cells and medium solution containing no adhesive agents were added to the test plate of the control group. Following this, the E-plate 16 was placed in the incubator. Cytotoxic values of adhesive systems at 24,48 , and $72 \mathrm{~h}$ were obtained by applying the extraction liquid at different times (24, 48, and $72 \mathrm{~h}$ ).

\section{Statistical Analysis}

SPSS 22.0 software was used for statistical analysis of the data obtained from this empirical study. The sphericity prerequisite was assessed with Mauchly's test of sphericity. In cases where the sphericity prerequisite was not provided, the difference between repeated measurements was determined by using the Greenhouse-Geise test. ANOVA test was performed for measurements between more than two independent groups. Posthoc Tukey's test was used for pairwise

Table 3. Mean \pm Standard error of cell proliferation values of tested universal adhesive systems

\begin{tabular}{lccc}
\hline Cell Proliferation $(\%)$ & $\mathbf{2 4} \mathbf{~ h}$ & $\mathbf{4 8 ~ h}$ & $\mathbf{7 2 ~ h}$ \\
\hline Control & $0.23 \pm 0.04^{\mathrm{Aa}}$ & $0.20 \pm 0.04^{\mathrm{Ab}}$ & $0.15 \pm 0.04^{\mathrm{Ac}}$ \\
G-Premio Bond & $0.19 \pm 0.04^{\mathrm{Ba}}$ & $0.17 \pm 0.05^{\mathrm{Bb}}$ & $0.12 \pm 0.04^{\mathrm{Bc}}$ \\
Tokuyama Universal Bond & $0.10 \pm 0.06^{\mathrm{Ca}}$ & $0.08 \pm 0.04^{\mathrm{Cb}}$ & $0.05 \pm 0.03^{\mathrm{Cc}}$ \\
Universal Bond Quick & $0.13 \pm 0.05^{\mathrm{Da}}$ & $0.11 \pm 0.05^{\mathrm{Db}}$ & $0.07 \pm 0.04^{\mathrm{Dc}}$ \\
Prime\&Bond Universal & $0.15 \pm 0.06^{\mathrm{Ea}}$ & $0.12 \pm 0.05^{\mathrm{Eb}}$ & $0.08 \pm 0.05^{\mathrm{Ec}}$ \\
Single Bond Universal & $0.13 \pm 0.05^{\mathrm{Fa}}$ & $0.10 \pm 0.04^{\mathrm{Fb}}$ & $0.06 \pm 0.04^{\mathrm{Fc}}$ \\
\hline
\end{tabular}

*Different letters within columns and lines indicate statistically significant differences. (Uppercases represent columnar differences intergroup, while lowercases represent linear differences intragroup). 


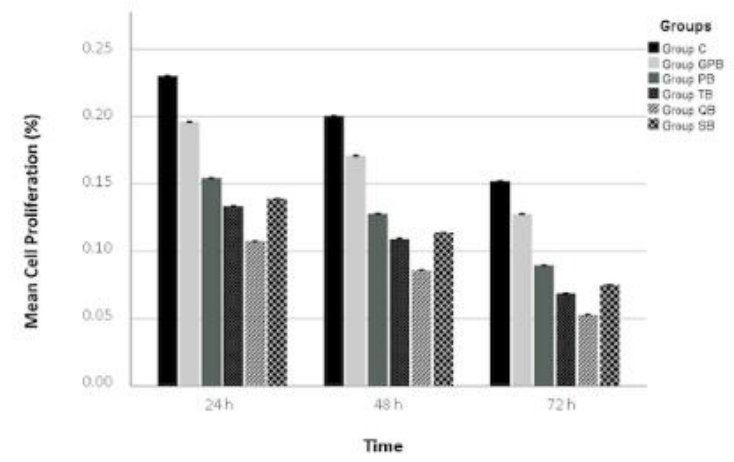

Figure 1. Comparison of mean cell proliferation (\%) of all groups at 24,48 and $72 \mathrm{~h}$

When all groups were compared with the control group, there was a statistically significant difference in all time values in terms of cytotoxicity $(\mathrm{p}<0.05)$. The lowest cytotoxicity value was observed at $24 \mathrm{~h}$ of G-Premio Bond, while the highest cytotoxicity value was found at $72 \mathrm{~h}$ of Tokuyama Universal Bond. Cell proliferation (\%) seen between control and other groups in all time periods ( $24 \mathrm{~h}, 48 \mathrm{~h}$, and $72 \mathrm{~h}$ ) are shown in Figures $2,3,4,5,6$.

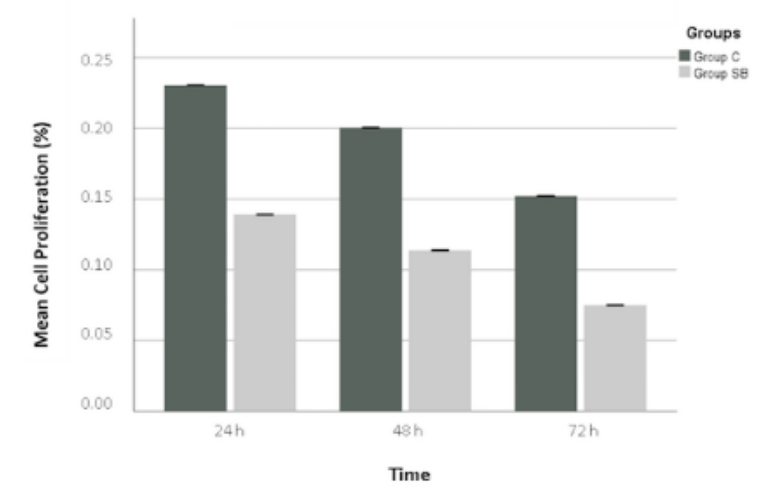

Figure 2. Comparison of mean cell proliferation (\%) between control and G-Premio Bond groups at 24, 48 and $72 \mathrm{~h}$

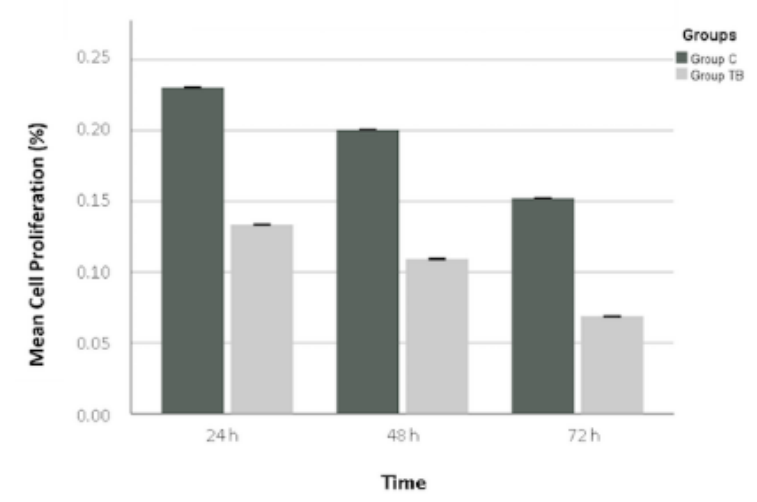

Figure 3. Comparison of mean cell proliferation (\%) between control and Prime\&Bond Universal groups at 24, 48 and $72 \mathrm{~h}$

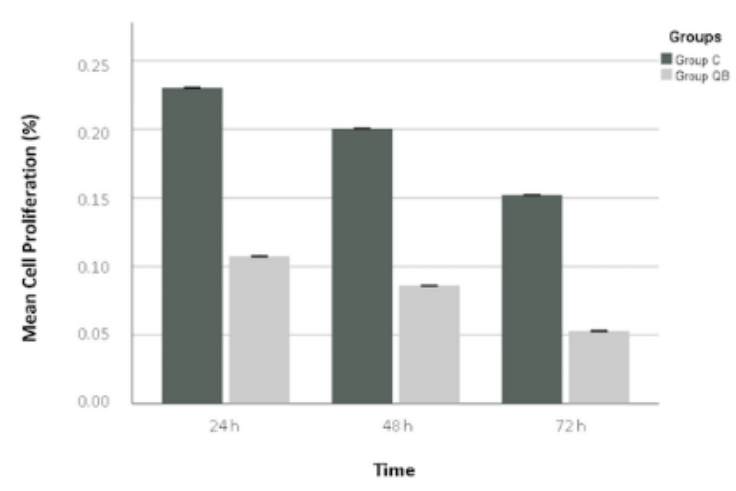

Figure 4. Comparison of mean cell proliferation (\%) between control and Single Bond Universal groups at 24, 48 and $72 \mathrm{~h}$

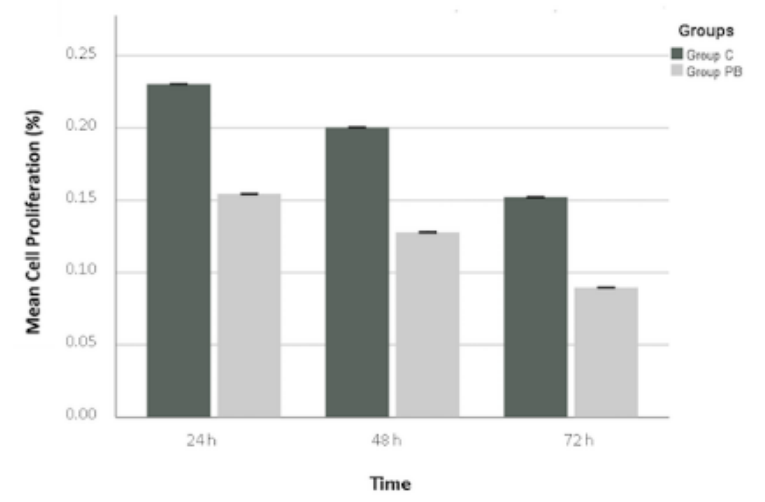

Figure 5. Comparison of mean cell proliferation (\%) between control and Tokuyama Universal Bond groups at 24, 48 and $72 \mathrm{~h}$

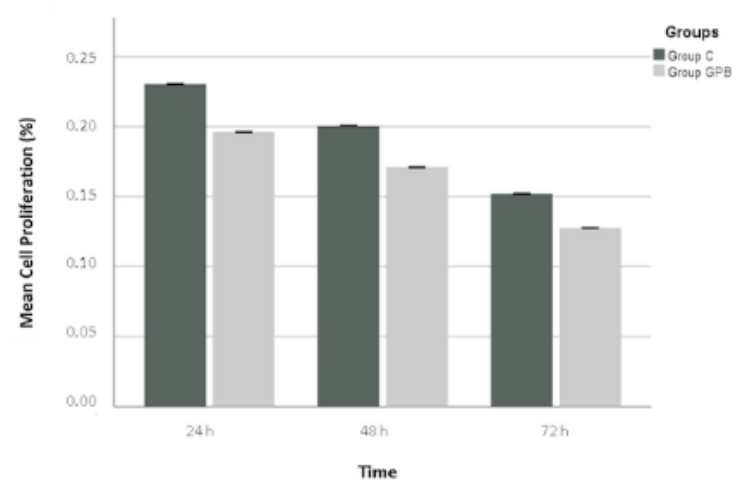

Figure 6. Comparison of mean cell proliferation (\%) between control and Universal Bond Quick groups at 24, 48 and $72 \mathrm{~h}$

\section{DISCUSSION}

Dental materials which have different contents are offered on the market by the manufacturers in adhesive dentistry with the advancement of technology each passing day. During the evaluation of a newly developed material, its physical, mechanical and biological properties should be taken into consideration. ${ }^{1,29}$ The number and variety of tests evaluating the biocompatibility of materials have increased with developed products. ${ }^{9}$ The adhesive systems used in restorative dentistry have different cytotoxic properties. Da Silva et al. ${ }^{30}$ examined the biocompatibility of the 
four different generations of adhesive systems and reported that the universal bond systems had the lowest cytotoxic effect on pulpal cells.

Previous research has determined that different universal adhesives have different compositions, such as HEMA, Bis-GMA, UDMA and PENTA, as well as biphenyl dimethacrylate (BPDM), CQ, MDP, polyalkenoic acid, acetone and ethanol, different $\mathrm{pH}$ and polymerization methods. ${ }^{8,9}$ Several studies have shown that these parameters impact the cytotoxicity of the agent used. ${ }^{10-12}$ Therefore, in this experimental study, five different universal adhesive systems with different contents, $\mathrm{pH}$ and, different polymerization methods were investigated. Acetone-based G-Premio Bond ( $\mathrm{pH}<2$ ), Tokuyama Universal Bond $(\mathrm{pH}>2)$, ethanol-based Prime \& Bond Universal $(\mathrm{pH}>2.5)$, Universal Bond Quick $(\mathrm{pH}>2)$ and Single Bond Universal $(\mathrm{pH}>2.5)$, which contain one or more of the resin monomers, were preferred for use in this study.

The cell type in which the dental materials are in contact with the cytotoxicity is important with the in-vitro studies. Especially in dentistry, using Balb 3T3 or L929 mouse fibroblasts cell cultures to evaluate cytotoxicity is recommended. ${ }^{31-33}$ L929 is a continuous cell culture line with a wide range of use as a standard in cytotoxicity testing of dental materials. ${ }^{34}$ In a previous study examining cytotoxicity, a dental material showed similar effects on L929 mouse fibroblasts and gingival fibroblasts. ${ }^{12}$

Biological events (cell proliferation, vitality, toxicity, the demonstration of the physical situation of the cells) can be analysed in real time by the xCELLigence system. ${ }^{35}$ The greatest advantage of this system is that the respective number of cells in each well of the E-plate 16, the proliferation, attachment and spreading of the cells can be monitored every 15 min. ${ }^{36}$ Data from cells in the wells are monitored simultaneously on the connected computer. ${ }^{37}$ This property allows for instant changes, such as stopping the experiment and adding a new substance. ${ }^{36}$ With the xCELLigence system, it is also possible to observe and evaluate the real-time analysis without the need for staining or marking the cells. In methods such as MTT, XTT and staining methods, it is not possible to use existing cells for different purposes after end-point analysis. Obtaining limited data with three different measurements in a 72-hour experiment using methods sensitive to human error is another disadvantage. In contrast, it is possible to receive cellular data every 15 seconds with realtime analysis using the xCELLigence system. The basic working principle in obtaining data in new systems is based on impedance measurements; therefore the cells used in the xCELLigence system can be evaluated with another test. ${ }^{38}$ For example, when a material is evaluated in terms of cytotoxicity, cells are collected from the wells when needed and information about the genotoxicity is obtained by evaluating the oxidative stress level. While only one parameter is evaluated with classical methods, general data (cell proliferation, cell apoptosis, morphological change in cell membrane) can be examined with xCELLigence. The xCELLigence device offers economical, comprehensive and more accurate study to researchers. ${ }^{37}$

Previous studies have reported that different monomers are released from resin-based dental materials during or after polymerization..$^{39-41}$ The monomers released from the materials in the different compositions determine the biocompatibility. ${ }^{13}$ Although it is possible to fully polymerize the monomer in theoretically, one study that this transformation is at most $70 \%$ with conventional light sources. ${ }^{42}$ With the increasing power of light sources, the polymerization percentage of monomers is expected to increase. In addition, as heat is generated during the polymerization of dental materials, the dentinal fluid in the tubules moves towards the pulp and the released monomers reach the pulp. These issues increase the damage to the pulp caused by heat. In a study, an $800 \mathrm{~mW}$ light device (20 s) and a 650 $\mathrm{mW}$ light device (30 s) were used for polymerizing the resin composite, and the number of live lymphocyte cells was examined at the end of the experiment. ${ }^{43}$ High cell viability was detected in the group that was applied for a longer time at low power density compared to the group that was applied for a shorter time at high power density. 
In the literature, there have been many studies about the release of monomers time-dependent due to insufficient polymerization. Some studies indicate that 1-7 days are required for full-swing, while in some studies it has been stated that 30 days should be waited. ${ }^{12,44}$ In addition, there is a positive connection between the contact time of the adhesive systems to the dentine and the cytotoxic effect of the monomers in the contents of the adhesive. Ratanasathien et al. ${ }^{16}$ found, that the duration of action of monomers released from adhesive agents has a strong effect on the toxicity of adhesive systems. In this study, measurements at $24 \mathrm{~h}, 48 \mathrm{~h}$ and 72 hours were obtained in order to evaluate the short-medium-long-term cytotoxic effects of adhesive systems, and it was observed that the cytotoxicity varied depending on the time of exposure.

Some components of resin-based dental materials are considered to be cytotoxic; furthermore, cytotoxic effects of Bis-GMA, TEGDMA, UDMA and HEMA have been investigated. In previous studies, the cytotoxicity of monomers has been shown to be the following: Bis-GMA> UDMA> TEGDMA> HEMA. ${ }^{16,36}$ The cytotoxicity values obtained as a result of this study are achieved by a similar mechanism. G-Premio Bond and Prime \& Bond Universal adhesive systems that did not contain any of these resin monomers showed lower cytotoxicity. Also, Tokuyama Universal Bond which contains resin monomers such as Bis-GMA, UDMA and HEMA, had the highest cytotoxic value.

Koulaouzidou et al. ${ }^{45}$ examined the cytotoxic effects of three different adhesive systems on fibroblast cells and reported that the XP Bond group showed the highest cytotoxic value. This study identified that UDMA and TEGDMA monomers in the content of the XP Bond system are responsible for this result. The same study reported that the molecular weight and components of resin monomers may also affect this result: HEMA, which has a low molecular weight, has a less toxic effect than Bis-GMA, UDMA and TEGDMA. While Bis-GMA and UDMA showed highly toxic effects, HEMA and TEGDMA had moderately toxic effects. ${ }^{16,42,46}$ In present study, the
Tokuyama Universal Bond group, which includes Bis-GMA, TEGDMA and HEMA monomers had the highest cytotoxicity value, while G-Premio Bond and Prime\&Bond Universal adhesives which do not include any of these monomers, had the lowest cytotoxicity value.

Several studies reported that camphorquinone, which acts as a photo initiator in adhesive systems, is both cytotoxic and mutagenic. ${ }^{40,47}$ In this present study, it is possible that camphorquinone, which is a component of the Prime \& Bond Universal adhesive system, may be responsible for the cytotoxic effect of this adhesive agent.

In a study in the literature, the cytotoxicity of composite resin and adhesive systems was examined immediately and following a seven days incubation period, it was reported that all samples were cytotoxicity, but it decreased after seven days. ${ }^{48}$ Extraction fluid containing residual monomers released from dental materials was removed to evaluate the samples, and only samples were used. However, in this study, the samples were kept in the extraction liquid for $72 \mathrm{~h}$ and cytotoxic effects were determined using the extraction fluid. In the study of Franz et al. ${ }^{48}$, although the toxic effect of all groups is consistent with this research, it assumed that the reason for the decrease cytotoxic effect at the end of $72 \mathrm{~h}$ was performed by removing the extraction fluid of the material.

In the study of Yasuda et $a .^{22}$, the cytotoxic effect of five different adhesive systems (AQ Bond Plus, Clearfil Tri-S Bond, G-Bond, Adper Prompt and Absolute) in human pulp cells was examined when compared with the polymerized samples and those applied without polymerization, lower cytotoxicity was observed in the polymerized group. Additionally, the cytotoxic effect was significantly higher at $72 \mathrm{~h}$ compared to $24 \mathrm{~h}$. This finding is consistent with the present study, in which comparison of $24 \mathrm{~h}$ and $72 \mathrm{~h}$ groups, revealed significantly more toxic effects present at $72 \mathrm{~h}$.

Schedle et al. ${ }^{12}$ examined, the cytotoxic effects of composite, adhesive system and / or primer combinations, including experimental 
groups for both chemical polymerization and light polymerization of the Optibond adhesive system. On the $2^{\text {nd }}$ and $7^{\text {th }}$ day of the experiment, the number of cells (\%) was lower in the chemical polymerization of the Optibond adhesive system. Moreover, in this study, Tokuyama Universal Bond, which is chemically polymerized, was shown to be associated with lower cellular proliferation compared to four other universal adhesive systems polymerized with the LED light device (G-Premio Bond, Prime\&Bond Universal, Single Bond Universal and Quick Bond Universal).

In another study ${ }^{49}$, the cytotoxicity of Single Bond ( $\mathrm{pH}=4.3$ ), Clearfil SE Bond (primer $\mathrm{pH}=1.9$, bond $\mathrm{pH}=2.8)$, Xeno III Bond ( $\mathrm{pH}=1.0)$, Clearfil Protect Bond (primer $\mathrm{pH}=1.9$, bond $\mathrm{pH}=2.8$ ) and Adper Prompt Bond ( $\mathrm{pH}=0.8$ ) which have different $\mathrm{pH}$ values were investigated by MTT method, and the lowest cytotoxicity was found in the Adper Prompt Bond adhesive system with the lowest $\mathrm{pH}$ value. In this study, the G-Premio Bond adhesive system $(\mathrm{pH}=1.5)$ had the lowest $\mathrm{pH}$ value and demonstrated the lowest cytotoxicity. Similarly, when the Single Bond Universal $(\mathrm{pH}=2.7)$ and Universal Bond Quick $(\mathrm{pH}=2.3)$ were compared, the Universal Bond Quick adhesive system, which has a lower $\mathrm{pH}$, showed lower cytotoxicity.

According to our results, the null hypothesis that all five different universal adhesive systems with different monomer content, $\mathrm{pH}$ level, and polymerization technique will have different cytotoxic effects was accepted.

This experimental study has several limitations, including the inability to fully mimic the in vivo environment of the in vitro study. In addition, cytotoxicity was not followed for time periods longer than $72 \mathrm{~h}$, and mouse fibroblast cells were used. Very few studies to date have evaluated the cytotoxicity of adhesive systems using the xCELLigence system. Ours is the first study to compare the cytotoxic effects of five different universal adhesive systems with the xCELLigence device; however, additional studies are required to clearly elucidate these cytotoxic effects.

\section{CONCLUSIONS}

According to the results of this research, all the universal adhesive systems used in were found to have a significant cytotoxic effect on the L929 mouse fibroblast cell line compared to the control group, and it was concluded that this effect increased time-depending ( $24 \mathrm{~h}, 48 \mathrm{~h}$ and $72 \mathrm{~h}$ ). It was assumed that the cytotoxic effect of adhesive systems on L929 mouse fibroblast cells is related to the increase in residual monomer concentration released from adhesives.

\section{ACKNOWLEDGMENTS}

All procedures performed in this study were in accordance with the ethical standards of the Ethics Committee, University Gaziantep (process no. 2018/374), and with the 1964 Helsinki Declaration and its later amendments or comparable ethical standards. The authors would like to thank Prof. Dr. Esra CAN EROĞLU, Prof. Dr. İhsan HUBBEZOĞLU, Assist. Prof. Dr. Ceylan HEPOKUR for their contributions

\section{CONFLICTING INTERESTS}

The author(s) declared no potential conflicts of interest with respect to the research, authorship, and/or publication of this article.

\section{FUNDING}

This study was supported by Gaziantep University, Scientifics Research Section with DHF.UT.19.03 project number.

\section{REFERENCES}

1. Schmalz G. Concepts in biocompatibility testing of dental restorative materials. Clin Oral Invest. 1998;1:154-162.

2. Perdigão J. Dentin bonding - Variables related to the clinical situation and the substrate treatment. Dent Mater. 2010;26:24-37.

3. Tay FR, Pashley DH. Aggressiveness of contemporary self-etching systems: I: Depth of penetration beyond dentin smear layers. Dent Mater. 2001;17:296-308.

4. Hanabusa M, Mine A, Kuboki T, Momoi Y, Van Ende A, Van Meerbeck B, De Munck. Bonding effectiveness of a new 'multi-mode'adhesive to enamel and dentine. J Dent. 2012;40:475-484. 
5. Perdigão J, Sezinando A, Monteiro PC. Laboratory bonding ability of a multi-purpose dentin adhesive. Am J Dent. 2012;25:153.

6. Muñoz MA, Luque I, Hass V, Reis A, Loguercio AD, Bombarda NHC. Immediate bonding properties of universal adhesives to dentine. J Dent. 2013;41:404-411.

7. Lawson NC, Robles A, Fu CC, Lin CP, Sawlani K, Burgess JO. Two-year clinical trial of a universal adhesive in total-etch and self-etch mode in non-carious cervical lesions. J Dent. 2015;43:1229-1234.

8. Al-Dawood A, Wennberg A. Biocompatibility of dentin bonding agents. Dent Traumatol. 1993;9:1-7.

9. Kusdemir M, Gunal S, Ozer F, Imazato S, Izutani N, Ebisu S, Blatz MB. Evaluation of cytotoxic effects of six self-etching adhesives with direct and indirect contact tests. Dent Mater J. 2011;30:799-805.

10. Schmalz G, Arenholt-Bindslev D. Biocompatibility of dental materials. 2009, Springer 1.

11. Lanza CRM, Costa CAS, Furlan M, Alecio A, Hebling J. Transdentinal diffusion and cytotoxicity of self-etching adhesive systems. Cell Biol Toxicol 2009;25:533.

12. Schedle A, Franz A, Raush-Fan X, Spittler A, Lucas T, Samorapoompichit P, Sperr W, Boltz-Nitulescu G. Cytotoxic effects of dental composites, adhesive substances, compomers and cements. Dent Mater. 1998;14:429-440.

13. Geurtsen W. Biocompatibility of resin-modified filling materials. Crit Rev Oral Biol Med. 200;11:333-355.

14. Nakabayashi N, Kojima K, Masuhara E. The promotion of adhesion by the infiltration of monomers into tooth substrates. J Biomed Mater Res. 1982; 16:265-273.

15. Schmalz G. Materials science: biological aspects. J Dent Res. 2002;81:660.

16. Ratanasathien S, wataha JC, Hanks CT, Dennison JB. Cytotoxic interactive effects of dentin bonding components on mouse fibroblasts. J Dent Res. 1995;74:1602-1606.

17. Tay FR, Carvalho R, Sado H, Pashley DH.Effect of smear layers on the bonding of a self-etching primer to dentin. J Adhes Dent. 200;2:99-116.
18. Bergenholtz G. Evidence for bacterial causation of adverse pulpal responses in resin-based dental restorations. Crit Rev Oral Biol Med. 200;11:467-480.

19. Chen, RS, Liu CC, Tseng WY, Jeng JH, Lin CP. Cytotoxicity of three dentin bonding agents on human dental pulp cells. J Dent. 2003;31:223-229.

20. Hashieh IA, Cosset A, Franquin JC, Camps J. In vitro cytotoxicity of one-step dentin bonding systems. J Endod. 1999;25:89-92.

21. Karapınar-Kazandag M, Bayrak ÖF, Yalvaç ME, Ersev H, Tanalp J, Şahin F, Bayırlı G. Cytotoxicity of 5 endodontic sealers on L929 cell line and human dental pulp cells. Int Endod J. 2011; 44:626-634.

22. Yasuda $Y$, Inuyama $H$, Maeda $H$, Akamine $A$, Nör JE, Saito T. Cytotoxicity of one-step dentin-bonding agents toward dental pulp and odontoblast-like cells. J Oral Rehabil. 2008;35:940-946.

23. Murray PE, About I, Lumley PJ, Franquin JC, remusat $\mathrm{M}$, Smith AJ. Cavity remaining dentin thickness and pulpal activity. Am J Dent. 2012;15:41-46.

24. Albuquerque M, Pegoraro M, Mattei G, Reis A, Loguercio AD. Effect of double-application or the application of a hydrophobic layer for improved efficacy of one-step self-etch systems in enamel and dentin. Oper Dent. 2008;33:564-570.

25. Perdigão J, Munoz MA, sezinando A, LuquelMartinez IV, Staichak R, reis A, Loguerco AD. Immediate adhesive properties to dentin and enamel of a universal adhesive associated with a hydrophobic resin coat. Oper Dent. 2014;39:489-499.

26. Altintas SH, Usumez A. Evaluation of monomer leaching from a dual cured resin cement. J Biomed Mater Res B. 2008;86:523-529.

27. Chen C, Niu LN, Xie H, Zhang ZY, Zhou LQ, Jiao K, Chen JH, Pashley DH, Tay FR. Bonding of universal adhesives to dentine-Old wine in new bottles? J Dent. 2015; 43:525-536.

28. Ergün G, Eğilmez F, Üçtaşı MB, Yilmaz Ş. Effect of light curing type on cytotoxicity of dentine-bonding agents. Int Endod J. 2006;40:216-223.

29. Kılıç K, Kesim B, Sümer Z, Polat Z, Kesim S. Evalution of Biocompatibility of Full Ceramics with MTT. J Health Sci. 2010;19:125-132. 
30. da Silva JM, Rodrigues JR, Camargo CHS, Fernandes VVB, Hiller KA, Schweiki H, Schmalz G. Effectiveness and biological compatibility of different generations of dentin adhesives. Clin Oral Investig. 2014;18:607-613.

31. Wataha J, Rueggeberg FA, Lapp CA, Lewis CA, Lockwood PE, Ergle JW, Mettenburg DJ. In vitro cytotoxicity of resin-containing restorative materials after aging in artificial saliva. Clin Oral Investig. 1999;3:144-149.

32. Thonemann B, Schmalz G, Hiller KA, Schweikl H. Responses of L929 mouse fibroblasts, primary and immortalized bovine dental papilla-derived cell lines to dental resin components. Dent Mater. 2002;18:318-323.

33. Bouillaguet S, Shaw L, Gonzalez L, Wataha JC, Krejci L. Long-term cytotoxicity of resin-based dental restorative materials. J Oral Rehabil. 2002;29:7-13.

34. Wataha JC, Craig RG, Hanks C. Precision of and new methods for testing in vitro alloy cytotoxicity. Dent Mater. 1992;8:65-70.

35. Ke N, Wang $X, X u \quad X$, Abassi YA. The xCELLigence system for real-time and label-free monitoring of cell viability, in Mammalian Cell Viability. Mammalian Cell Viability. 2011;740:33-43.

36. Urcan E, Haertel U, Styllou M, Hickel R, Scherthan H, Reichl FX. Real-time xCELLigence impedance analysis of the cytotoxicity of dental composite components on human gingival fibroblasts. Dent Mater.201;26:51-58.

37. Malkoç S, Öztürk F, Çörekçi B, Bozkurt BS, Hakki SS. Real-time cell analysis of the cytotoxicity of orthodontic mini-implants on human gingival fibroblasts and mouse osteoblasts. Am J Orthod Dentofac. 2012;141:419-426.

38. Golke A, Cymerys j, Stonska A, Dzieciakowski T, Chmielewska a, Tucholska A,Banbura MW. The xCELLigence system for real-time and label-free analysis of neuronal and dermal cell response to Equine Herpesvirus type 1 infection. Pol $\mathbf{J}$ Vet Sci. 2012;15:151-153.

39. Ruyter I. Physical and chemical aspects related to substances released from polymer materials in an aqueous environment. Adv Dent Res. 1995;9:344-347.
40. Geurtsen W, Spahl W, Leyhausen G. Variability of cytotoxicity and leaching of substances from four lightcuring pit and fissure sealants. J Biomed Mater Res. 1999; 44:73-77.

41. Gerzina T, Hume W. Diffusion of monomers from bonding resin-resin composite combinations through dentine in vitro. J Dent. 1996;24:125-128.

42. Geurtsen W, Lehmann F, Spahl W, Leyhausen G. Cytotoxicity of 35 dental resin composite monomers/ additives in permanent $3 \mathrm{~T} 3$ and three human primary fibroblast cultures. J Biomed Mater Res. 1998; 41:474480 .

43. Knezevic A, Zeljezic D, Kopjar N, Tarle Z. Cytotoxicity of composite materials polymerized with LED curing units. Oper Dent. 2008;33:23-30.

44. Taira M, Nakao H, Matsumoto $T$, Takahashi J. Cytotoxic effect of methyl methacrylate on 4 cultured fibroblasts. Int J Prosthodont. 2000;13:311-315.

45. Koulaouzidou EA, Papazisis KT, Yiannaki E, Palaghias G, Antoniades MH. Effects of dentin bonding agents on the cell cycle of fibroblasts. J Endod. 2009;35:275-279.

46. Rakich DR, Wataha JC, Lefebvre CA, Weller RN. Effects of dentin bonding agents on macrophage mitochondrial activity. J Endod. 24(8):528-533.

47. Al-Hiyasat AS, Darmani H, Elbetieha AM. Leached components from dental composites and their effects on fertility of female mice. Eur J Oral Sci. 2009;112:267272.

48. Franz A, König F, Lucas T, Watts DC, Schedle A. Cytotoxic effects of dental bonding substances as a function of degree of conversion. Dent Mater. 2009;25:232-239.

49. Schmalz G, Schuster U, Koch A, Schwiki H. Cytotoxicity of low $\mathrm{pH}$ dentin-bonding agents in a dentin barrier test in vitro. J Endod. 2002; 28:188-192. 